\title{
Tropical and Extratropical SST Effects on the Midlatitude Storm Track
}

\author{
Masaru INATSU, Hitoshi MUKOUGAWA ${ }^{1}$ \\ Graduate School of Environmental Earth Science, Hokkaido University, Sapporo, Japan \\ and \\ Shang-Ping XIE \\ International Pacific Research Center/SOEST and Department of Meteorology, University of Hawaii, \\ Honolulu, Hawaii, USA
}

(Manuscript received 31 May 2001, in revised form 1 December 2001)

\begin{abstract}
Effects of zonal variations in sea surface temperature (SST) on synoptic eddy activity are examined using an atmospheric general circulation model under the perpetual January and the aqua-planet conditions. In the presence of zonal variations in tropical SST, upper tropospheric zonal wind displays large zonal asymmetry and the storm track is located downstream of the maximum westerly speed. When only extratropical SST varies in the east-west direction, a storm track develops along the sharp meridional SST gradient despite a nearly zonally uniform westerly jet in the upper troposphere. The latter result suggests that zonal variations in upper tropospheric westerlies contribute to but are not necessary for zonally confined storm tracks.
\end{abstract}

\section{Introduction}

In the Northern Hemisphere winter, storm tracks, regions with large activity of synopticscale transient eddies, are located downstream of the westerly jet cores in both the Pacific and Atlantic sectors (Blackmon et al. 1977; Lau and Wallace 1979). The formation of the storm tracks ultimately results from zonal variations in surface conditions such as sea surface temperature (SST), land-sea contrast, and orography. We focus on the effect of SST in this paper.

It is now well established that tropical SST anomalies excite stationary eddies in the ex-

Corresponding author: Masaru Inatsu, Graduate School of Environmental Earth Science, Hokkaido University, N10W5, Kita-ku, Sapporo, 060-0810, Japan.

E-mail: inaz@ees.hokudai.ac.jp

1 Present affiliation: Disaster Prevention Research Institute, Kyoto University, Uji, Kyoto, Japan.

(C) 2002, Meteorological Society of Japan tratropics that induce changes in storm tracks. (See Lau 1997 and Okumura et al. 2001 for reviews of Pacific and Atlantic cases, respectively.) In fact, the feedback from the transient eddies has been shown to be important for maintaining the extratropical stationary eddies (e.g., Lau 1988; Ting and Held 1990). Determining the effects of extratropical SST variations, on the other hand, proves elusive (Robinson 2000). While some report significant stationary eddy response (Palmer and Sun 1985), some other studies found weak or no significant response in the time-mean fields in the upper troposphere. For instance, conducting perpetual January atmospheric general circulation model (AGCM) experiments, Kushnir and Held (1996) suggested that extratropical SST anomalies induce a shallow and weak baroclinic response near the surface but detected little equivalent barotropic response, a result they also confirmed with idealized aqua-planet 
experiments. Such apparently mutualcontradictory results may be due to the high sensitivity of stationary eddy response to the mean state that varies seasonally and from one model to another (Peng et al. 1997).

While the effects of extratropical SST on stationary eddies in the upper troposphere are difficult to determine, it is known to weather forecasters that extratropical storms tend to develop along mid-latitude SST fronts like the Kuroshio Extension in the Pacific and the North Atlantic Current in the Atlantic (e.g., Sinclair 1997). There are good physical grounds for this empirical observation. Many theoretical studies have suggested that baroclinicity defined as

$$
\sigma_{\mathrm{BC}}=0.31 f\left|\frac{\partial \boldsymbol{u}}{\partial z}\right| / \mathscr{N}
$$

is a quantity closely related to the development of synoptic eddies (Lindzen and Farrell, 1980). Here $f=f(\phi)$ is the Coriolis parameter, $\mathscr{N}=\mathscr{N}(z)$ is buoyancy frequency, and $\left|\frac{\partial \boldsymbol{u}}{\partial z}\right|$ is vertical wind shear. Observed high values of $780 \mathrm{hPa}$ baroclinicity east of Asia and North America (Hoskins and Valdes 1990) are due to a number of factors: land-sea contrast, upper level westerly jet maximum, and local SST. It appears, if not impossible, to isolate each of these causes in observations and in simulation under realistic settings.

This note describes and contrasts the preliminary results from two idealized AGCM that are designed to isolate the tropical and extratropical SST effects on the storm track, respectively. The main result is that despite the virtual absence of upper-level stationary eddies, a well-defined storm track develops along a mid-latitude SST front in support of empirical observations cited above. The next section describes the model and experimental settings. Section 3 presents the stationary and transient eddy response to zonal variations in SST. Section 4 is a summary.

\section{Models and experiments}

We use an AGCM developed at the University of Tokyo Center for Climate System Research (CCSR) and National Institute for Environmental Studies (NIES), which is the community model for Japanese universities.
The model is based upon the primitive equations on the sphere and includes parameterization of physical processes such as radiation, cumulus convection, large-scale cloud condensation, turbulent mixing, gravity wave drags, surface flux, and ground hydrology. This model simulates the atmospheric circulation rather realistically under observed boundary conditions (Shen et al. 1998; Numaguti 1999) and has been coupled with ocean models to study the climate and its variability (Watanabe et al. 1999; Xie and Saito 2001). Here we use a version that is triangle-truncated at the zonal wavenumber 42 (T42) and has 20 sigma levels (L20) in the vertical. The same set of experiments were performed at the T21 L20 resolution, yielding qualitatively similar results.

In this study, the model surface is all covered by water and SST is prescribed. The model is run under the perpetual January conditions. We analyze twice-daily data sets for 1500 days after a one-year spin-up period. All the boundary conditions except for SST distribution are zonally uniform. Two experiments are performed. In one of them, SST is given as

$$
\begin{aligned}
T_{*}(\lambda, \phi)= & T_{0}+T_{2} \sin ^{2}\left(\phi-\phi_{0}\right) \\
& +\frac{\alpha}{2} \sin \lambda \exp \left(-\frac{\phi^{2}}{200}\right),
\end{aligned}
$$

where $T_{0}=301.15 \mathrm{~K}, T_{2}=-32.0 \mathrm{~K}, \phi_{0}=8^{\circ} \mathrm{S}$, and $\alpha=5 \mathrm{~K}$. Here the longitude $\lambda$ and the latitude $\phi$ are measured in degrees (Fig. 1a). In this T-run, a warm (cold) water pool is centered on $90^{\circ} \mathrm{E}\left(90^{\circ} \mathrm{W}\right)$ in the tropics while SST is zonally uniform in the extratropics. In the other experiment, we focus instead on extratropical SST effect (E-run hereafter) by prescribing a SST distribution

$$
\begin{aligned}
& T_{*}(\lambda, \phi)=T_{0}+T_{2} \sin ^{2}\left(\phi-\phi_{0}\right)+\frac{\beta}{2} \sin \lambda \\
& \quad \times\left[\exp \left\{-\frac{\left(\phi-\phi_{1}\right)^{2}}{200}\right\}-\exp \left\{-\frac{\left(\phi-\phi_{2}\right)^{2}}{200}\right\}\right],
\end{aligned}
$$

where $\phi_{1}=30^{\circ} \mathrm{N}, \phi_{2}=50^{\circ} \mathrm{N}$, and $\beta=5 \mathrm{~K}$ (Fig. $1 b)$. In this E-run, the meridional SST gradient displays a wavenumber-one zonal variation in the extratropics, reaching a maximum at $90^{\circ} \mathrm{E}$ $\left(90^{\circ} \mathrm{W}\right)$. 

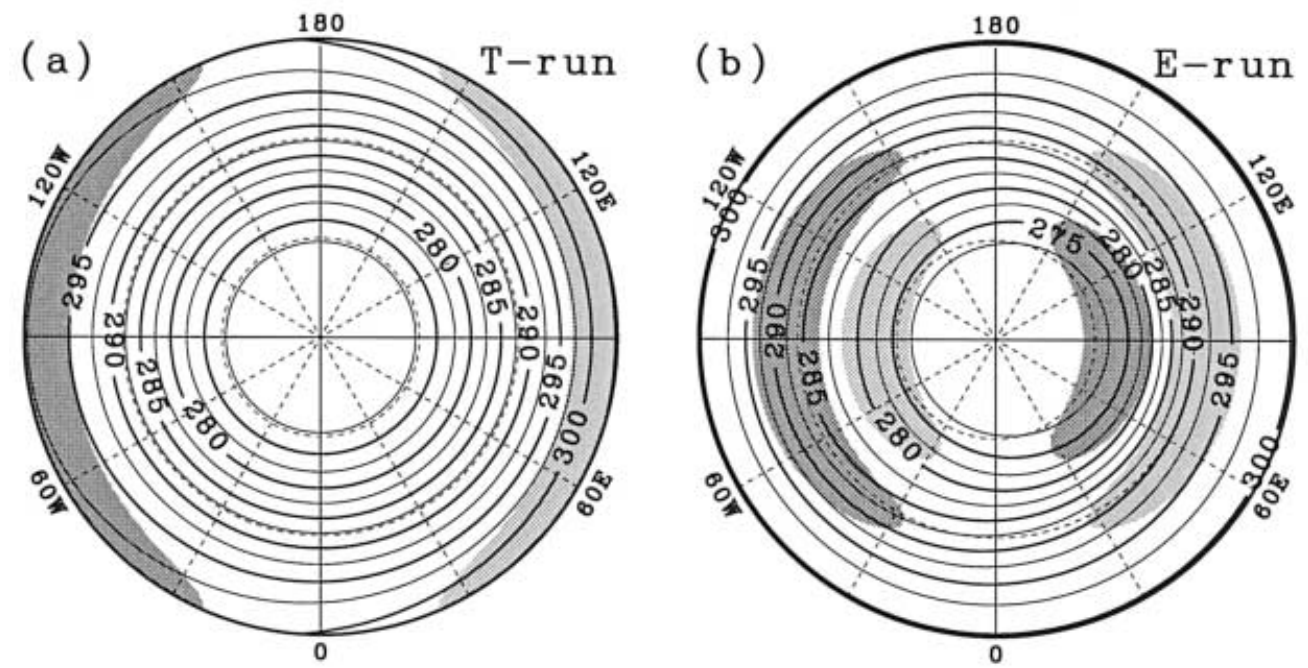

Fig. 1. SST (contours) and its deviation from the zonal mean (shading) for the T-run (a) and the E-run (b). Contour intervals are $2.5 \mathrm{~K}$, with light (heavy) shading $>1(<-1) \mathrm{K}$. The outer edge of the map is on the equator, and the short dashed circles are along $30^{\circ} \mathrm{N}$ and $60^{\circ} \mathrm{N}$.

\section{Results}

Figures $2 \mathrm{a}$ and $2 \mathrm{~b}$ display zonal wind speed (contours) and stationary waves (shade) at $250 \mathrm{hPa}$. Tropical SST variations excite large stationary waves in the T-run, resulting in substantial zonal variations in zonal wind in the extratropics. Maximum (minimum) westerly speed is found around $90^{\circ} \mathrm{E}\left(90^{\circ} \mathrm{W}\right)$ in the midlatitudes, sandwiched between subtropical anticyclone (cyclone) and subarctic cyclone (anticyclone) (Inatsu et al. 2002). The subtropical (subarctic) stationary eddies are baroclinic (barotropic) in the vertical (Inatsu et al. 2000). In the E-run, by contrast, stationary eddies are very weak in response to extratropical SST variations. As a result, upper tropospheric zonal wind is nearly zonally uniform. This is consistent with Inatsu et al. (2000) who, using the same AGCM, find that extratropical land-sea contrast in the zonal direction is much less effective in forcing zonal variations in the upper tropospheric westerly jet.

Figures $2 \mathrm{c}$ and $2 \mathrm{~d}$ show three measures of the storm track: root-mean-square variances of 2.5-6 days band-pass filtered geopotential height (hereafter RMSZ; solid contours) at $250 \mathrm{hPa}$, precipitation (dashed), and northward heat flux (shade) at $700 \mathrm{hPa}$ by transient fluctuations of period $<10$ days (Blackmon 1976).
In both the $\mathrm{T}$ and $\mathrm{E}$ runs, synoptic eddy activity reaches its meridional maximum along the $40^{\circ} \mathrm{N}$ circle and displays significant zonal variations. In the zonal direction, the upper-level storm track (RMSZ $>60 \mathrm{~m}$ ) is roughly colocated with but slightly shifted downstream of the maxima of northward heat flux and precipitation. This downstream shift is particularly pronounced in the T-run. In the T-run, RMSZ exceeds $60 \mathrm{~m}$ over one-third of the $40^{\circ} \mathrm{N}$ latitude circle from $150^{\circ} \mathrm{E}$ to $60^{\circ} \mathrm{W}$. The zonal contrast in its precipitation is also weaker than in the E-run. These results suggest a scenario that tropical SST forcing forms the zonally confined storm track via exciting stationary eddies and modulating the subtropical westerly jet.

In the E-run with zonal SST variations in the extratropics but not in the tropics, RMSZ displays strong zonal variations with a clear peak around $140^{\circ} \mathrm{E}$. The overall level of storm activity in the E-run is lightly higher than in the Trun, with the RMSZ $=60 \mathrm{~m}$ contour covering a larger zonal extent between $30^{\circ} \mathrm{E}$ to $150^{\circ} \mathrm{W}, 30^{\circ}$ more than in the T-run. Heat flux and precipitation both have well-defined maxima around $90^{\circ} \mathrm{E}$ in the E-run, coinciding with the maximum meridional gradient of prescribed SST. These results from the E-run demonstrate that the zonal SST variations in the extratropics are very effective in forcing a localized storm track 

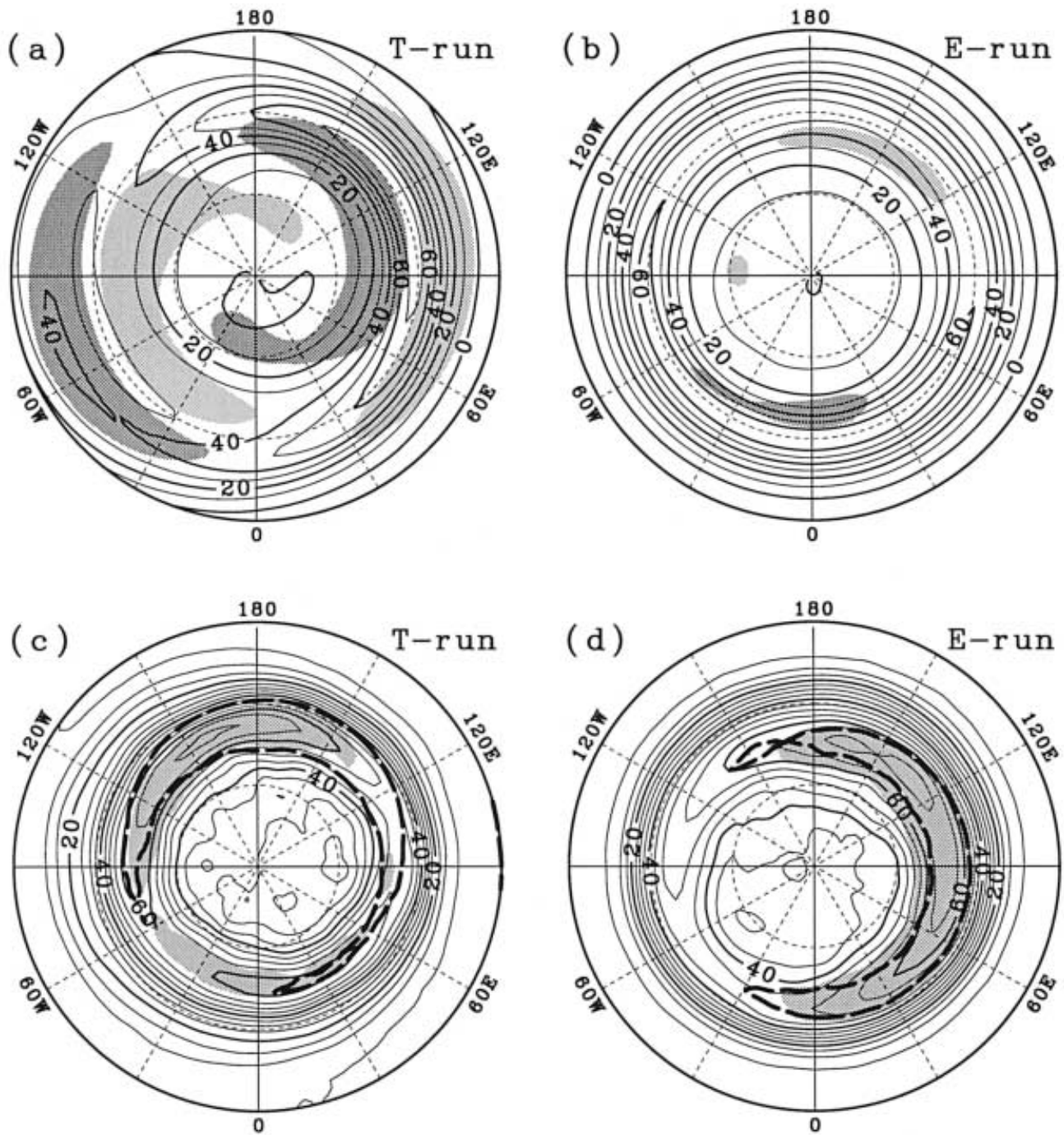

Fig. 2. Time-mean zonal wind speed (contours) and geopotential height deviation from the zonal mean (shading) on the $250 \mathrm{hPa}$ surface for the T-run (a) and the E-run (b). Contour intervals are $10 \mathrm{~m} \mathrm{~s}^{-1}$ with light (heavy) shading $>60(<-60) \mathrm{m} .250 \mathrm{hPa}$ root-mean-square band-pass filtered geopotential height (solid contours at intervals of $5 \mathrm{~m}$ ), $700 \mathrm{hPa}$ synoptic eddy heat flux (shade $>10 \mathrm{~K} \mathrm{~m} \mathrm{~s}^{-1}$ ), and the $120 \mathrm{~W} \mathrm{~m}^{-2}$ precipitation contour in heavy dotted line for the T-run (c) and the E-run (d).

in the upper troposphere without much help of stationary eddies.

In order to further examine the relationship between storm tracks and time-mean fields, we show the vertical structure of storm activity, northward heat flux and vertical shear of zonal wind as a function of longitude and pressure in Fig. 3. In the T-run, the mean vertical wind shear shows largest zonal asymmetry in the upper troposphere, peaking at $90^{\circ} \mathrm{E}$. In the lower troposphere, significant zonal variations in the vertical shear remain presumably due to the surface drag acting upon barotropic westerly wind, reaching a maximum at $150^{\circ} \mathrm{E}$ that roughly coincides with the maximum northward heat transport. This indicates that the enhanced baroclinicity in the near-surface layer is responsible for the in-situ growth and downstream development of transient eddies. The maximum in storm activity in the upper tro- 
(a) T-run

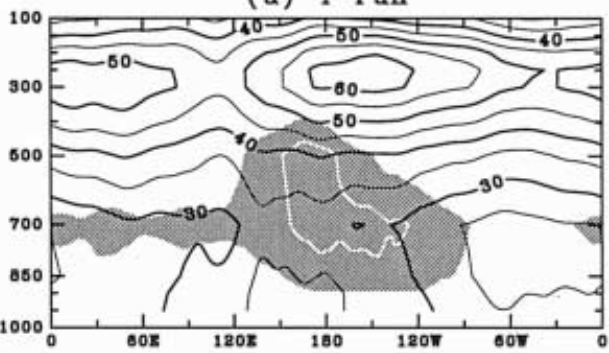

(c) T-run

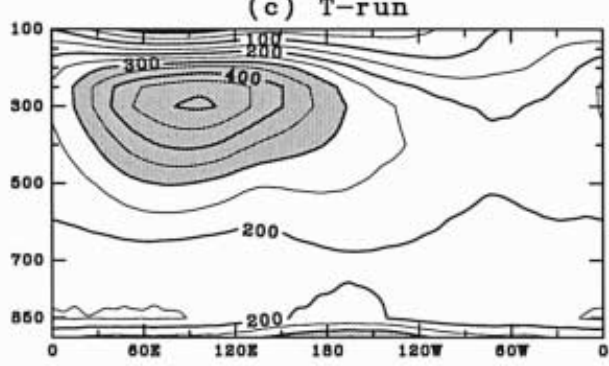

(e) T-run

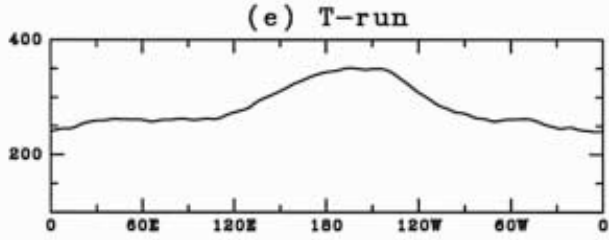

(b) E-run

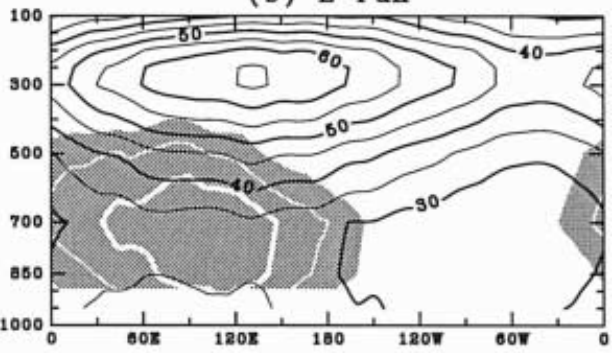

(d) E-run

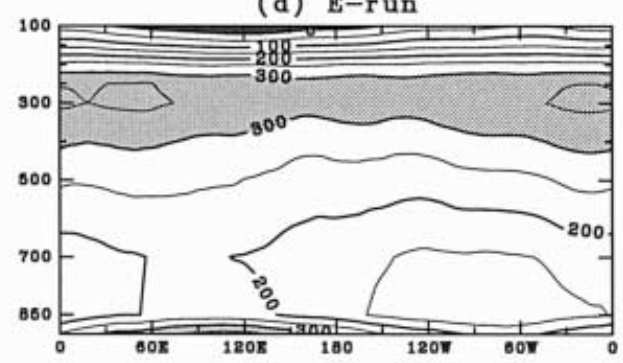

(f) E-run

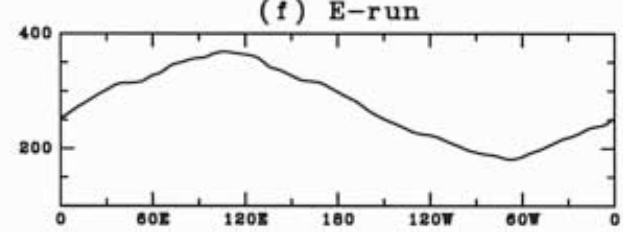

Fig. 3. Zonal cross-sections averaged between $30^{\circ} \mathrm{N}$ and $48^{\circ} \mathrm{N}$ for the T-run (left panels) and the E-run (right). (a and b): Root-mean-square band-pass filtered geopotential height (contours at intervals $5 \mathrm{~m}$ ). Synoptic eddy heat flux is shaded in the regions $>8 \mathrm{~K} \mathrm{~m} \mathrm{~s}^{-1}$ and contoured at 10 (12) $\mathrm{K} \mathrm{m} \mathrm{s}^{-1}$ with thin (thick) white line. The vertical derivative of zonal wind speed (in day ${ }^{-1}$ ) as a function of longitude and pressure (c and d) and at $900 \mathrm{hPa}$ (e and f). Contour intervals are 50 day $^{-1}$, with light (heavy) shade $>300(<0)$ day $^{-1}$.

posphere is slightly shifted east of that in the lower levels, which indicates the upward and downstream propagation of baroclinic disturbances excited near the surface.

The vertical shear near the surface in the Erun is simply the thermal wind balancing the enhanced SST gradient at $90^{\circ} \mathrm{E}$. This maximum wind shear leads to a large growth of baroclinic transient eddies as indicated by the maximum heat transport. The maximum storm activity in the lower troposphere is almost coincident with this strong SST gradient zone while it is shifted slightly downstream in the upper levels.

Under the aqua-planet conditions, the static stability of the lower atmosphere does not vary much in the zonal direction and baroclinicity is hence mostly a function of vertical shear. Figure 4 shows the baroclinicity at $900 \mathrm{hPa}$, which in both the $\mathrm{T}$ and $\mathrm{E}$ runs, is nearly co-located with precipitation and eddy heat flux but is shifted upstream of maximum storm activity in the upper troposphere. In both the runs, lowlevel baroclinicity is a very good indicator of the growth of baroclinic eddies, their subsequent downstream development and the formation of storm tracks. These results support the linear model study of Hoskins and Valdes (1990). Our AGCM experiments demonstrate that variations in low-level baroclinicity can be caused by the teleconnection from the tropics or alternatively by changes in local SST gradient. 

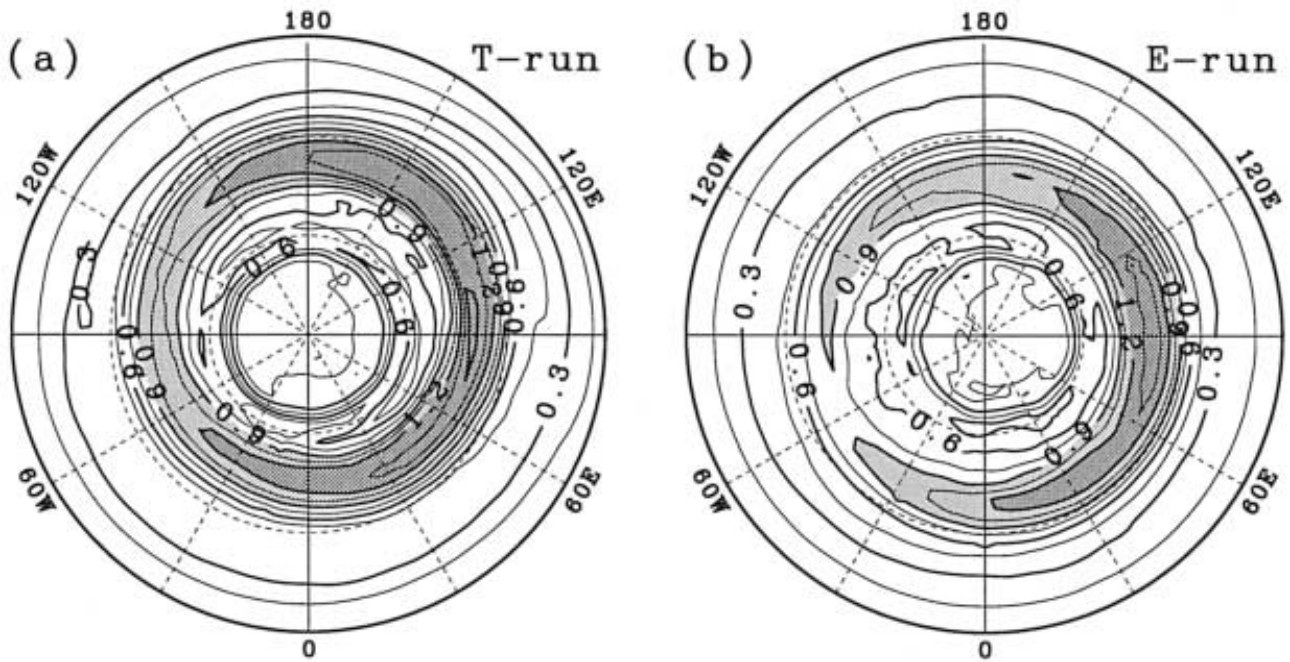

Fig. 4. Baroclinicity at $900 \mathrm{hPa}$ for the T-run (a) and the E-run (b). Contour intervals are 0.15 day $^{-1}$, with light (heavy) shade $>0.9(1.2)$ day $^{-1}$.

\section{Concluding remarks}

We have carried out two idealized aquaplanet experiments to investigate the effect of SST on mid-latitude storm tracks. Tropical SST forcing generates large extratropical stationary eddies that modulate the storm track distribution. A zonal enhancement of extratropical SST gradient generates little stationary eddies but leads to large zonal variations in the storm track. In both cases, vertical wind shear or baroclinicity near the sea surface is found to be closely related to the growth of baroclinic disturbances and the development of upper-level storm tracks. The zonal variations in low-level vertical wind shear can be forced both remotely by tropical SST and locally by extratropical SST. The stationary eddy response in the upper troposphere to extratropical SST anomalies is small in our model. Given the strong disagreement among AGCMs on whether and how stationary eddies respond to extratropical SST variations (Robinson 2000), the high sensitivity of storm tracks we demonstrate here has important implications for coupled oceanatmosphere modeling.

In the real atmosphere, both tropical and extratropical SST variations contribute cooperatively to the formation of storm tracks. In the North Pacific, for instance, the warm water pool in the equatorial Indo-western Pacific is responsible for a strong westerly jet core over Japan (Inatsu et al. 2000) and along the Kuroshio-Oyashio Extension where strong meridional SST gradient is observed. Both the westerly speed maximum in the upper troposphere and the local SST front are favorable for the downstream development of transient eddies as demonstrated in this study.

Here we have interpreted our results in terms of zonal variations in the growth of baroclinic disturbances, but changes in the dissipation rate of synoptic eddies can also lead to zonal variations in storm tracks. One of the promising candidates for dissipation mechanism is ageostrophic energy transfer in the meridional direction. Synoptic eddies tend to be strained in the terminus of storm tracks (e.g., Shutts 1983), where poleward and equatorward ageostrophic eddy energy transfer may take place. Another candidate is barotropic energy conversion from eddies to the time-mean flow in the diffluent and confluent environment (Whitaker and Dole 1995). In the T-run, the enhanced westerly jet area from $0^{\circ}$ to $90^{\circ} \mathrm{E}$, which may lead to strong horizontal deformation, corresponds to small eddy heat flux and precipitation. Thus, the assumption that the dissipation rate is zonally uniform may break down in the T-run where the westerly wind displays robust zonal variations and the associated large deformation field may cause baro- 
tropic decay. Further investigation into the mechanisms for zonally confined storm tracks is beyond the scope of this short note and is a subject of our ongoing research.

\section{Acknowledgements}

This paper is dedicated to Atushi Numaguti, who spearheaded the development of the CCSR/ NIES AGCM and then generously made it available to the larger community. Like so many other users of this AGCM, we are deeply indebted to him. We thank M. Kimoto for the permission to use CCSR/NIES AGCM version 5.4, I. Hirota and M. Nonaka for helpful comments, and two anonymous reviewers for comments that led to improved presentation. This study was supported by Japan Society of Promoting Sciences, Grants-in-Aid for Scientific Research (C) (2) 12640417 and Scientific Research on Priority Areas (B) (2) 11219203 from the Ministry of Education, Culture, Sports, Science and Technology of Japan, Center for Climate System Research of University of Tokyo, Frontier Research System for Global Change and US National Science Foundation under grant ATM-0104468. The manuscript was completed during a visit by the lead author to IPRC. The IPRC contribution No. 143 and SOEST contribution No. 5915. The figures were produced with the GFD-DENNOU Library.

\section{References}

Blackmon, M.L., 1976: A climatological spectral study of the $500 \mathrm{mb}$ geopotential height of the Northern Hemisphere. J. Atmos. Sci., 33, 1607-1623.

_, J.M. Wallace, N.-C. Lau, and S.L. Mullen, 1977: An observational study of the Northern Hemisphere wintertime circulation. J. Atmos. Sci., 34, 1040-1053.

Hoskins, B.J. and P.J. Valdes, 1990: On the existence of storm-tracks. J. Atmos. Sci., 47, 1854-1864.

Inatsu, M., H. Mukougawa, and S.-P. Xie, 2000: Formation of subtropical westerly jet core in an idealized AGCM. Geophys. Res. Lett., 12, 529532.

$\longrightarrow,-$, and $\longrightarrow$ 2002: Stationary eddy response to surface boundary forcing: Idealized GCM experiments. J. Atmos. Sci., 59, 18981915.

Kushnir, Y. and I.M. Held, 1996: On the equilibrium response to North Atlantic SST anomalies. J. Climate, 9, 1208-1220.
Lau, N.-C., 1988: Variability of the observed midlatitude storm tracks in relation to lowfrequency changes in the circulation pattern. J. Atmos. Sci., 45, 2718-2743.

, 1997: Interactions between global SST anomalies and the midlatitude atmospheric circulation. Bull. Amer. Meteor. Soc., 78, 2133 .

_ of horizontal transport by transient eddies in the Northren Hemisphere wintertime circulation. J. Atmos. Sci., 36, 1844-1861.

Lindzen, R.S. and B. Farrell, 1980: A simple approximate result for the maximum growth rate of baroclinic instabilities. J. Atmos. Sci., 37, 1648-1654.

Numaguti, A., 1999: Origin and recycling process of precipitating water over the Eurasian continent: Experiment using an atmospheric general circulation model. J. Geophys. Res., 104, 1957-1972.

Okumura, Y., S.-P. Xie, A. Numaguti, and Y. Tanimoto, 2001: Tropical Atlantic air-sea interaction and its influence on the NAO. Geophys. Res. Lett., 28, 1507-1510.

Palmer, T.N. and Z. Sun, 1985: A modelling and observational study of the relationship between sea surface temperature in the northwest Atlantic and atmospheric general circulation. Quart. J. Roy. Meteor. Soc., 111, 947-975.

Peng, S., W.A. Robinson, and M.P. Hoerling, 1997: The modeled atmospheric response to midlatitude SST anomalies and its dependence on background circulation states. J. Climate, 10, 971-987.

Robinson, W.A., 2000: Review of WETS-The workshop on extratropical SST anomalies. Bull. Amer. Meteor. Soc., 81, 567-577.

Shen, X., M. Kimoto, and A. Sumi, 1998: Landsurface processes associated with interannual variability of broad-scale Asian monsoon simulated by the CCSR/NIES AGCM. J. Meteor. Soc. Japan, 76, 217-236.

Shutts, G.J., 1983: The propagation of eddies in diffluent jetstreams: eddy vorticity forcing of "blocking" flow fields. Quart. J. Roy. Meteor. Soc., 109, 737-761.

Sinclair, M.R., 1997: Objective identification of cyclones and their circulation intensify and climatology. Wea. Forecasting, 12, 595-612.

Ting, M.-F. and I.M. Held, 1990: The stationary wave response to a tropical SST anomaly in an idealized GCM. J. Atmos. Sci., 47, 2546-2566.

Watanabe, M., M. Kimoto, T. Nitta, and M. Kachi, 1999: A comparison of decadal climate oscillation in the North Atlantic detected in observed 
and a coupled GCM. J. Climate, 12, 29202940.

Whitaker, J.S. and R.M. Dole, 1995: Organization of storm tracks in zonally varying flows. J. Atmos. Sci., 52, 1178-1191.
Xie, S.-P. and K. Saito, 2001: Formation and variability of a northerly ITCZ in a hybrid coupled AGCM: Continental forcing and oceanatmospheric feedback. J. Climate, 14, 12621276. 